\title{
The distribution of parenchyma, follicles, and lymphocyte subsets in thymus of patients with myasthenia gravis, with special reference to remission after thymectomy
}

Takeshi Mori, MD, ${ }^{a}$ Hiroaki Nomori, MD, PhD, ${ }^{a}$ Koei Ikeda, MD, PhD, ${ }^{a}$ Hironori Kobayashi, MD, ${ }^{a}$ Kazunori Iwatani, MD, and Toshiaki Kobayashi, MD, $\mathrm{PhD}^{\mathrm{b}}$

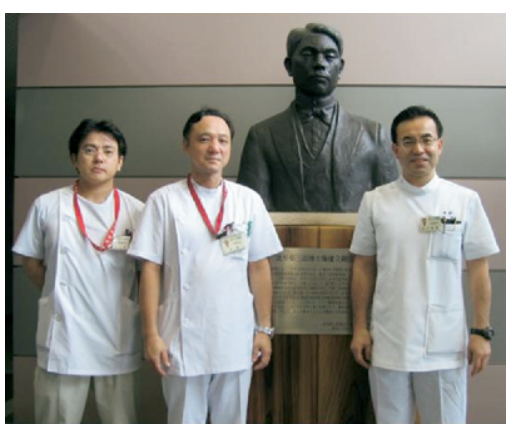

Drs Ikeda, Mori, and Nomori (left to right). The bronze statue is Dr Shibasaburo Kitasato.
From the Department of Thoracic Surgery, Graduate School of Medical Sciences, Kumamoto University, Kumamoto, Japan, and the Department of Assistive Diagnostic Technology, ${ }^{\mathrm{b}}$ National Cancer Center Hospital, Tokyo, Japan.

Supported, in part, by a Grant-in-Aid from the Ministry of Health, Labor and Welfare of Japan.

Received for publication Aug 6, 2006; revisions received Oct 7, 2006; accepted for publication Oct 23, 2006.

Address for reprints: Hiroaki Nomori, MD, $\mathrm{PhD}$, Department of Thoracic Surgery, Graduate School of Medical Sciences, Kumamoto University, 1-1-1 Honjo, Kumamoto 860-8556, Japan (E-mail: hnomori@ qk9.so-net.ne.jp).

J Thorac Cardiovasc Surg 2007;133:364-8

$0022-5223 / \$ 32.00$

Copyright (C) 2007 by The American Association for Thoracic Surgery

doi:10.1016/j.jtcvs.2006.10.026
Objective: We sought to examine the distribution of parenchyma, follicles, and lymphocyte subsets in the thymus of patients with myasthenia gravis and to identify determinants of remission after thymectomy.

Methods: Sixty patients with myasthenia gravis who underwent thymectomy were examined. The thymus was divided into upper, middle, and lower parts. The upper part was defined as the superior horn, the lower part as the inferior horn, and the middle part as tissue located between the 2 horns. The percentage of parenchyma was measured morphometrically. The degree of follicular hyperplasia was classified into 5 grades. The densities of $\mathrm{CD}^{+}, \mathrm{CD}^{+}$, and $\mathrm{CD} 8^{+}$lymphocytes were classified into 5 grades. The remission of myasthenia gravis after thymectomy was examined with those variables in each part of the thymus.

Results: The middle part had the highest percentage of parenchyma, the highest grade of follicular hyperplasia, and the highest density of $\mathrm{CD}^{+}, \mathrm{CD} 4^{+}$, and $\mathrm{CD} 8^{+}$ lymphocytes among the 3 parts $(P<.001-.05)$. The grades of follicular hyperplasia in the middle and lower parts were significantly higher in patients with improvement of myasthenia gravis than in those without $(P<.05)$. The densities of $\mathrm{CD}^{+}, \mathrm{CD}^{+}$, and $\mathrm{CD} 8^{+}$lymphocytes in the cortex of the middle part were significantly higher in patients with improvement than in those without improvement $(P<.01-.05)$.

Conclusions: The thymus has a heterogeneous distribution of parenchyma, follicles, and lymphocyte subsets. The middle part had the largest parenchyma, the highest grade of follicular hyperplasia, and the highest densities of $\mathrm{CD} 3^{+}, \mathrm{CD} 4^{+}$, and $\mathrm{CD} 8^{+}$ lymphocytes among the 3 parts of the thymus. The grade of follicular hyperplasia and the density of these lymphocyte subsets are predictive of improvement in myasthenia gravis after thymectomy.

$\mathrm{T}$ The grade of follicular hyperplasia (FH) in the thymus has been reported to be a significant factor for predicting remission of myasthenia gravis (MG) after thymectomy. ${ }^{1-4}$ However, it has not been determined whether the distribution of parenchyma and follicles is uniform in the thymus. If these distributions are not uniform, the part of the thymus that is most appropriate for predicting remission of MG after thymectomy requires clarification. To examine these issues, we studied the following: (1) the thymus was divided into the upper, middle, and lower parts; (2) the percentage of parenchyma, grade of $\mathrm{FH}$, and density of lymphocyte subsets in each part were investigated; and (3) the relationship between those variables and the remission of MG after thymectomy was analyzed.

\section{Materials and Methods}

One hundred six consecutive patients with MG were treated with extended thymectomy from 1997 through 2004 at the Department of Thoracic Surgery of Kumamoto University Hospital. 


\section{Abbreviations and Acronyms \\ $\mathrm{FH}=$ follicular hyperplasia \\ $\mathrm{MG}=$ myasthenia gravis}

Of the 106 patients, 60 were available for pathological examination of the upper, middle, and lower parts of the thymus (Table 1). We studied these 60 patients retrospectively. All 60 patients had an extended thymectomy or extended thymothymomectomy through a median sternotomy.

The thymus was divided into 3 parts (ie, upper, middle, and lower; Figure 1). The upper part of the thymus was defined as the bilateral superior horns. The lower part was defined as the bilateral inferior horns. The middle part was defined as the tissue between the upper and lower parts. After fixation with formalin, these 3 pieces were usually sliced at intervals of $10 \mathrm{~mm}$, resulting in an average of 16 tissue blocks (range, 5-55) submitted for pathological examination in each patient.

The percentage of parenchyma in each part of the thymus was measured by using the following method: (1) a hematoxylin and eosin-stained section was viewed under a macro lens and was displayed on the screen of a 3CCD digital color camera-computer system (FX380, Olympus Co); (2) the image of the whole of the selected section was outlined with a mouse on the screen, including both the parenchyma and adipose tissue, and the data were processed by using a computer, which calculated the total area; (3) the area of parenchyma was likewise calculated; and (4) the percentage of parenchyma was derived from the area of parenchyma divided by the total area.

The degree of FH of the thymus was classified into 5 grades according to the classification of the MG study group of the Ministry of Health and Welfare of Japan in 1977: grade 0, involuted thymus; grade I, accumulation of lymphocytes in the distended medulla; grade II, 1 follicle in 1 section; grade III, 2 to 4 follicles in 1 section; and grade IV, more than 5 follicles in 1 section or more than 1 follicle in each lobule.

An immunohistochemical analysis of lymphocytes using markers for CD3, CD4, and CD8 (Nichirei Co) was performed in each

\section{TABLE 1. Patient characteristics}

$\begin{array}{lc}\text { Male/female sex } & 16 / 44 \\ \text { Mean age, range (y) } & 51 \text { (13-80) } \\ \text { Grade of MG (Osserman) } & 6 \\ \text { I } & 32 \\ \text { II } & 20 \\ \text { III } & 2 \\ \text { IV } & 19 / 41 \\ \text { Thymoma/nonthymoma } & \\ \text { Outcome of operation } & 10 \\ \text { A } & 40 \\ \text { B } & 9 \\ \text { C } & 0 \\ \text { D } & 1 \\ \text { E } & 1\end{array}$

$M G$, Myasthenia gravis.

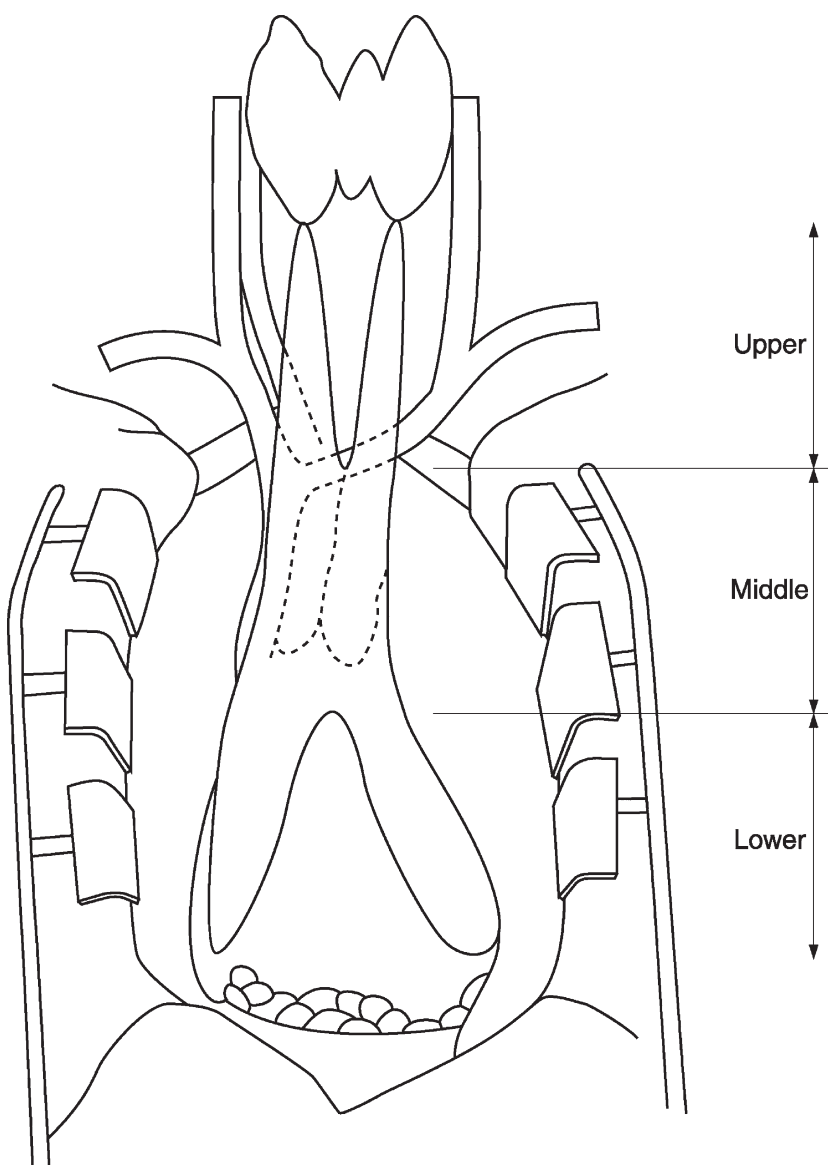

Figure 1. Definition of upper, middle, and lower parts of the thymus in the present study.

part. The density of lymphocyte subsets stained with these markers was classified into 5 grades: grade 0, no positive cells; grade I, scattered positive cells, grade II, fewer than half positive cells; grade III, more than half positive cells; and grade IV, almost all lymphocytes positive.

The postoperative outcome was obtained from hospital records or by means of telephone contact with a validated questionnaire. The investigation was approved by the institutional committee in 2005. The outcome of MG after thymectomy was classified from A to E: A, no symptoms and without medication; B, improvement and reduction in medication; $\mathrm{C}$, no change; $\mathrm{D}$, symptoms worse; and $\mathrm{E}$, death caused by MG.

Differences in the percentage of parenchyma among parts of the thymus were analyzed by using paired Student $t$ tests. Differences in the grade of FH and density of lymphocyte subsets in each part of the thymus were analyzed by using Wilcoxon signed-rank tests. Differences in the percentage of parenchyma between patients with and without improvement after thymectomy were analyzed with $t$ tests. Differences in the grade of FH and the density of lymphocyte subsets between the patients with improvement and those without improvement were analyzed by using MannWhitney $U$ tests. The Bonferroni test was used to determine 


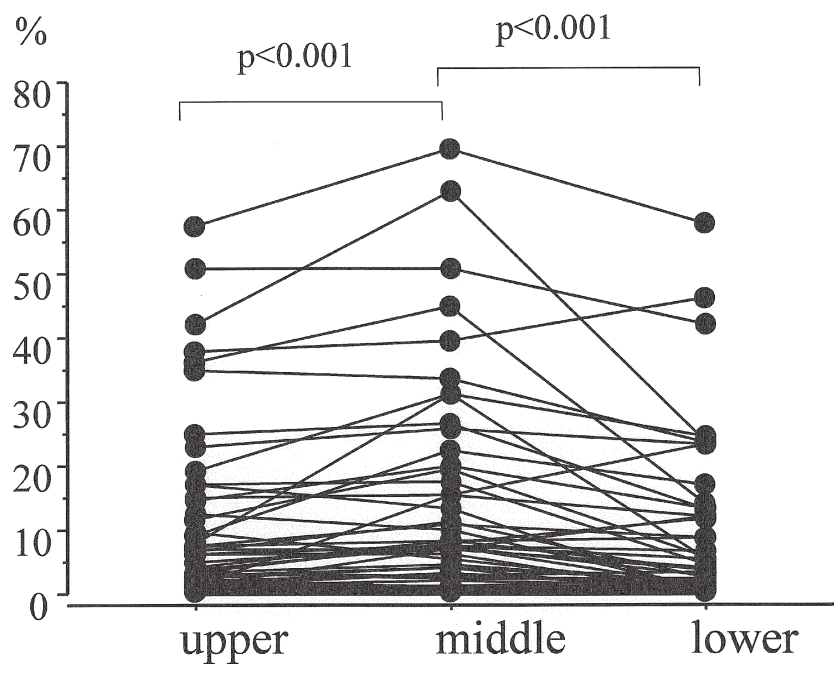

Figure 2. Percentage of parenchyma in each part of the thymus.

significance for comparisons among the 3 parts. All values in the text and tables are presented as means \pm standard deviation.

\section{Results}

The average of the total area of the upper, middle, and lower parts of the thymus was $4.2 \pm 3.3,7.6 \pm 4.3$, and $5.8 \pm 4.3$ $\mathrm{cm}^{2}$, respectively. The average area of parenchyma was $0.3 \pm 0.5,0.8 \pm 1.2$, and $0.4 \pm 0.7 \mathrm{~cm}^{2}$ in the upper, middle, and lower parts of the thymus, respectively. As a result, the average percentage of parenchyma was $9.2 \% \pm$ $13.1 \%, 11.8 \% \pm 15.7 \%$, and $7.5 \% \pm 12.0 \%$ in the upper, middle, and lower parts of the thymus, respectively (Figure 2). The percentage of parenchyma in the middle part of the thymus was significantly greater than in either the upper or lower parts $(P<.001)$.

The average grade of FH was $1.6 \pm 1.5,2.7 \pm 1.7$, and $1.4 \pm 1.6$ in the upper, middle, and lower parts of the thymus, respectively (Figure 3 ). The grade in the middle part was significantly higher than in the upper or lower parts $(P<.001)$.

The distributions of densities of $\mathrm{CD}^{+}, \mathrm{CD}^{+}$, and $\mathrm{CD} 8^{+}$lymphocytes in the cortex and medulla of each part of the thymus are summarized in Table 2. Although the density of $\mathrm{CD}^{+}$lymphocytes was significantly higher in the medulla than in the cortex of each part $(P<.0001)$, the densities of $\mathrm{CD}^{+}$and $\mathrm{CD} 8^{+}$lymphocytes were significantly higher in the cortex than in the medulla of each part $(P<.0001)$. In the cortex the densities of $\mathrm{CD}^{+}, \mathrm{CD}^{+}$, and $\mathrm{CD}^{+}$lymphocytes were significantly higher in the middle part than in the upper or lower parts $(P<.001-.05)$, except for difference in density of $\mathrm{CD}^{+}$lymphocytes between the upper and middle parts. In the medulla the densities of $\mathrm{CD} 4{ }^{+}$lymphocytes were significantly higher in the middle part than in the lower parts $(P<.05)$.

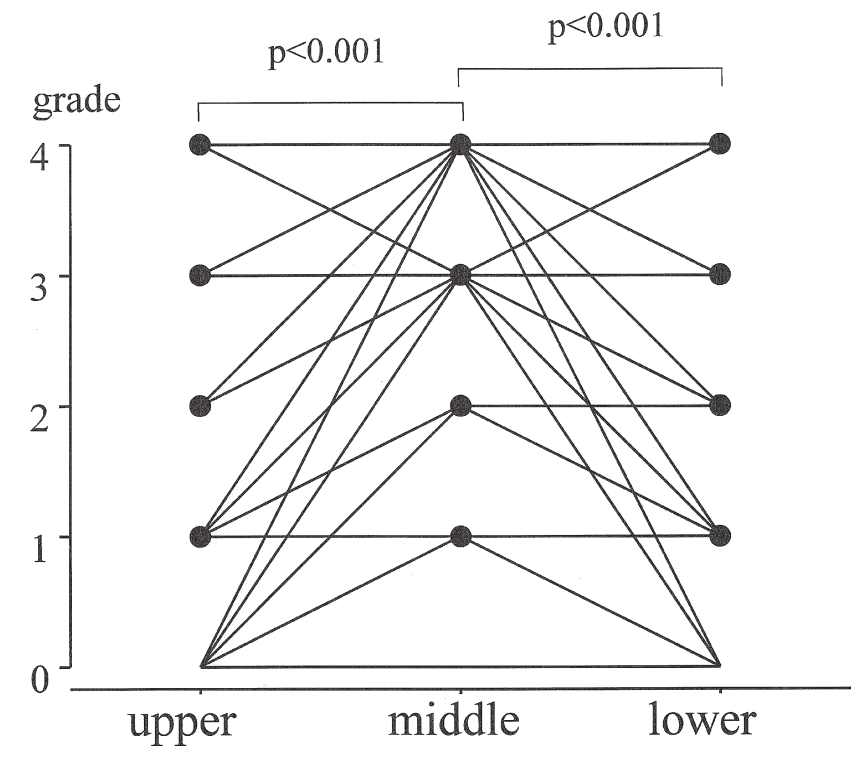

Figure 3. Grades of follicular hyperplasia in each part of the thymus.

The mean follow-up period after thymectomy was $49 \pm$ 28 months. A postoperative status of A was seen in 10 patients, $\mathrm{B}$ in 40 patients, $\mathrm{C}$ in 9 patients, and $\mathrm{E}$ in 1 patient. The patient with a postoperative status of $\mathrm{E}$ was a 79-yearold woman who died of a myasthenic crisis 49 months after thymectomy. Figure 4 shows the percentage of parenchyma of each part of the thymus in 50 patients with improvement (A and B) and 10 patients without improvement (C, D, and E), showing no significant difference between the 2 groups $(P=.16, .09$, and .12 , respectively $)$.

Figure 5 shows the grades of $\mathrm{FH}$ of each part of the thymus in patients with and without improvement. Although the grade of $\mathrm{FH}$ in the middle and lower parts was significantly higher in patients with improvement than in

TABLE 2. Distribution of density of lymphocyte subsets in the thymus

\begin{tabular}{llcc}
\hline & \multicolumn{3}{c}{ Density of lymphocyte subsets } \\
\cline { 2 - 4 } & \multicolumn{1}{c}{ CD3 $^{+}$} & CD4 $^{+}$ & CD8 $^{+}$ \\
\hline Cortex & & \\
Upper & $1.5 \pm 0.8$ & $1.6 \pm 0.9^{\dagger}$ & $2.0 \pm 0.8^{\dagger}$ \\
Middle & $1.5 \pm 0.7^{*}$ & $2.1 \pm 1.0^{\dagger}$ & $2.4 \pm 0.8^{\dagger}$ \\
Lower & $1.2 \pm 0.8^{*}$ & $1.6 \pm 1.1^{\dagger}$ & $2.0 \pm 1.1^{*}$ \\
Medulla & & & \\
Upper & $1.9 \pm 0.6$ & $1.2 \pm 0.8$ & $0.8 \pm 0.5$ \\
Middle & $2.0 \pm 0.7$ & $1.3 \pm 0.7^{*}$ & $0.9 \pm 0.5$ \\
Lower & $1.8 \pm 0.9$ & $1.1 \pm 0.8^{*}$ & $0.8 \pm 0.5$ \\
\hline
\end{tabular}

Upper, Upper part of the thymus; Middle, middle part of the thymus; Lower, lower part of the thymus. ${ }^{*} P<.05 ; \dagger P<.01 ; \ddagger P<.001$. 


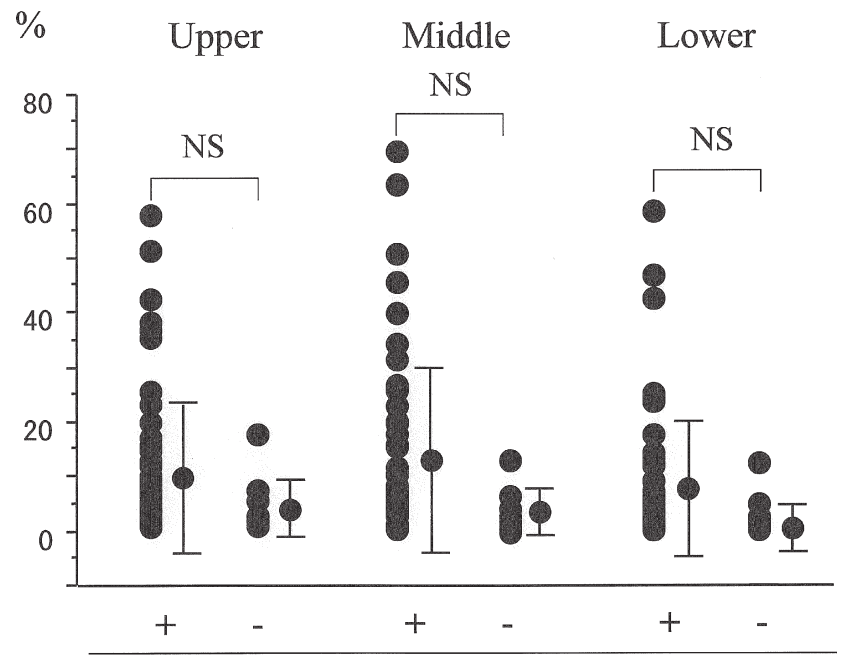

Improvement of $\mathrm{MG}(+: \mathrm{n}=50,-: \mathrm{n}=10)$

Figure 4. Differences in percentage of parenchyma in each part of the thymus between patients with and without improvement of myasthenia gravis after thymectomy. NS, Nonsignificant; MG, myasthenia gravis.

those without ( $P=.026$ and .044 , respectively), that in the upper part did not show a significant difference $(P=.16)$.

The densities of $\mathrm{CD}^{+}{ }^{+}, \mathrm{CD} 4^{+}$and $\mathrm{CD} 8^{+}$lymphocytes in the cortex and medulla of each part of the thymus in patients with improvement and in those without are summarized in

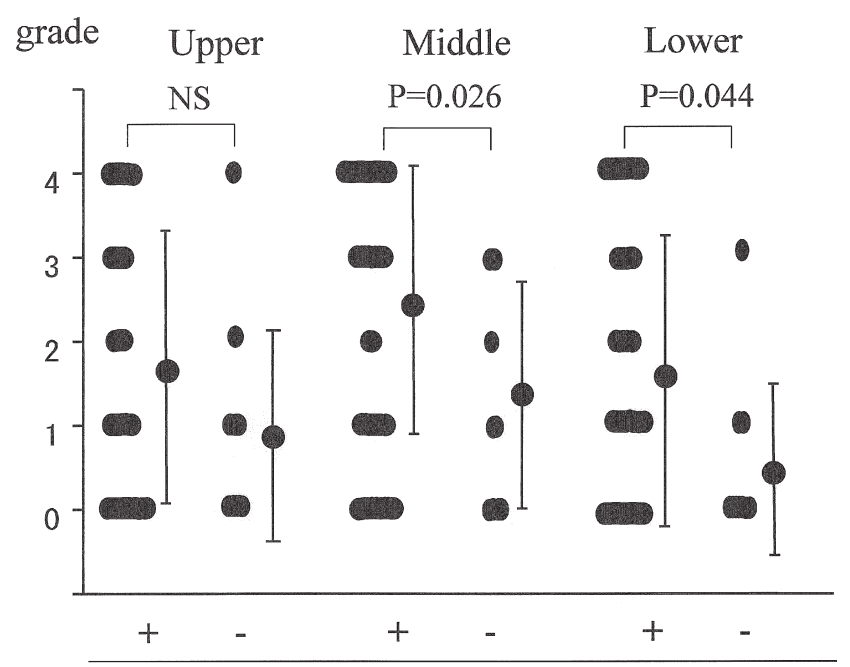

Improvement of $\mathrm{MG}(+: \mathrm{n}=50,-: \mathrm{n}=10)$

Figure 5. Differences in grade of follicular hyperplasia in each part of the thymus between patients with and without improvement of myasthenia gravis after thymectomy. NS, Nonsignificant; MG, myasthenia gravis.
TABLE 3. Density of $\mathrm{CD}^{+}, \mathrm{CD}^{+}$, and $\mathrm{CD8}^{+}$lymphocytes in each part of the thymus in patients with and without improvement of myasthenia gravis after thymectomy

\begin{tabular}{llcc}
\hline & \multicolumn{3}{c}{ Improvement of MG (+/-) } \\
\cline { 2 - 4 } & \multicolumn{3}{c}{ Density of: } \\
\cline { 2 - 4 } & CD3 $^{+}$ & CD4 $^{+}$ & CD8 $^{+}$ \\
\hline Cortex & & & \\
Upper & $1.6 / 0.9^{*}$ & $1.8 / 0.9 \dagger$ & $2.1 / 1.7$ \\
Middle & $1.6 / 0.9 \dagger$ & $2.2 / 1.4^{*}$ & $2.5 / 1.7^{*}$ \\
Lower & $1.8 / 1.1$ & $1.7 / 1.0$ & $2.1 / 1.8$ \\
Medulla & & & \\
Upper & $2.0 / 1.5^{*}$ & $1.3 / 0.8$ & $0.8 / 0.6$ \\
Middle & $2.1 / 1.6$ & $1.4 / 0.7 \dagger$ & $0.9 / 0.7$ \\
Lower & $1.8 / 1.5$ & $1.1 / 0.7$ & $0.8 / 0.7$ \\
\hline
\end{tabular}

Upper, Upper part of the thymus; Middle, middle part of the thymus; Lower, lower part of the thymus. $* P<.05, \dagger P<.01$.

Table 3. The results in the cortex were as follows: (1) although the densities of $\mathrm{CD}^{+}$lymphocytes in the upper and middle parts were higher in patients with improvement than in those without $(P=.012$ and .003 , respectively), the difference in the lower part was not significant $(P=.8)$; (2) although the densities of $\mathrm{CD}^{+}$lymphocytes in the upper and middle parts were higher in patients with improvement than in those without ( $P=.006$ and .015 , respectively), the difference in the lower part was not significant $(P=.8)$; and (3) although the density of $\mathrm{CD} 8^{+}$lymphocytes in the middle part was higher in the patients with improvement than in those without improvement $(P=.014)$, the differences in the upper and lower parts were not significant $(P=.1$ and .4 , respectively). In the medulla (1) the density of $\mathrm{CD}^{+}$ lymphocytes in the upper part was higher in patients with improvement than in those without $(P=.012)$, but the differences in the middle and lower parts were not significant $(P=.054$ and .3 , respectively); (2) the density of $\mathrm{CD} 4^{+}$lymphocytes in the middle part was higher in patients with improvement than in those without $(P=.007)$, but the differences in the upper and lower parts were not significant ( $P=.07$ and .13 , respectively); and (3) the density of $\mathrm{CD} 8^{+}$ lymphocytes did not show significant differences between patients with improvement and those without in any of the 3 parts $(P=.2, .2$, and .7 , respectively). Thus the differences in density of $\mathrm{CD}^{+}, \mathrm{CD}^{+}$, and $\mathrm{CD} 8^{+}$lymphocytes between patients with improvement and those without improvement were most significant in the cortex of the middle part of the thymus.

Pathological differences of thymus (eg, thymic hyperplasia, involuted thymus, and thymoma) did not affect the above results.

\section{Discussion}

The present study revealed 3 main points: (1) the middle part of the thymus had the highest percentage of paren- 
chyma, the highest grade of $\mathrm{FH}$, and the highest densities of lymphocyte subsets of the 3 parts; (2) the grades of FH in the middle and lower parts showed significant correlations with remission of MG after thymectomy, although that in the upper part did not; and (3) the densities of $\mathrm{CD}^{+}, \mathrm{CD}^{+}$ and $\mathrm{CD} 8^{+}$lymphocytes in the cortex of the middle part showed the greatest correlation with remission of MG after thymectomy, whereas those in the other parts showed less correlation.

The distribution of parenchyma, follicles, and lymphocyte subsets in the thymus has not been previously reported. The present study examined the differences of the percentage of parenchyma, grade of $\mathrm{FH}$, and densities of $\mathrm{CD}^{+}$, $\mathrm{CD} 4^{+}$, and $\mathrm{CD} 8^{+}$lymphocytes in the upper, middle, and lower parts of the thymus and revealed that the middle part had significantly higher values of these variables than the other parts. Therefore we conclude that the middle part of the thymus is the most representative area for examining parenchyma, follicles, and lymphocyte subsets.

It has been reported that patients with MG with FH of the thymus have higher remission rates after thymectomy than those without, ${ }^{1-4}$ but other authors have disputed this. ${ }^{5,6}$ The present study showed that the grades of FH in the middle and lower parts of the thymus were higher in patients with improvement than in those without improvement, although the grades in the upper part did not show a significant difference. Therefore to predict the outcome after thymec- tomy from the grade of $\mathrm{FH}$, the middle or lower part is more appropriate than the upper part.

The present study has shown that the thymus has a heterogeneous distribution of parenchyma, follicles, and T-cell subsets. The middle part had the largest parenchyma, the highest grade of $\mathrm{FH}$, and the highest density of T-cell subsets. Both the grade of FH and density of T-cell subsets in the middle part had significant correlation with improvement of MG after thymectomy. The middle part of the thymus is therefore the most representative area not only for histopathological examination but also for predicting improvement of MG after thymectomy.

\section{References}

1. Nicolaou S, Müller NL, Li DKB, Oger JJF. Thymus in myasthenia gravis: comparison of CT and pathologic findings and clinical outcome after thymectomy. Radiology. 1996;201:471-4.

2. Klein M, Granetzny A, Dauben HP, Schulte HD, Gams E. Early and late results after thymectomy in myasthenia gravis. A retrospective analysis Thorac Cardiovasc Surg. 1999;47:170-3.

3. Rubin JW, Ellison RG, Moore HV, Pai GP. Factors affecting response to thymectomy for myasthenia gravis. J Thorac Cardiovasc Surg. 1981;82:720-8.

4. Mantegazza R, Baggi F, Antozzi C, Confalonieri P, Morandi L, Bernasconi $\mathrm{P}$, et al. Myasthenia gravis (MG): epidemiological data and prognostic factors. Ann N Y Acad Sci. 2003;998:413-23.

5. Osserman KE, Genkins G. Studies in myasthenia gravis: review of a twenty-year experience in over 1200 patients. Mt Sinai J Med. 1971; 38:497-537

6. Blossom GB, Ernstoff RM, Howells GA, Bendick PJ, Glover JL. Thymectomy for myasthenia gravis. Arch Surg. 1993;128:855-62. 